\title{
Interaction of Protein Phosphatase $1 \delta$ with Nucleophosmin in Human Osteoblastic Cells
}

\author{
Tatsuji Hanejii ${ }^{1}$, Jumpei Teramachi ${ }^{1}$, Kanji Hirashima ${ }^{1}$, Koji Kimura $^{1}$ and \\ Hiroyuki Morimoto ${ }^{2}$
}

\begin{abstract}
${ }^{1}$ Department of Histology and Oral Histology, Institute of Health Biosciences, The University of Tokushima Graduate School, Kuramoto, Tokushima 770-8504, Japan and ${ }^{2}$ Department of Anatomy, School of Medicine, University of Occupational and Environmental Health, Yahatanishi, Kitakyushu 807-8555, Japan
\end{abstract}

Received August 25, 2011; accepted September 21, 2011; published online November 5, 2011

\begin{abstract}
Protein phosphorylation and dephosphorylation has been recognized as an essential mechanism in the regulation of cellular metabolism and function in various tissues. Serine and threonine protein phosphatases (PP) are divided into four categories: PP1, PP2A, PP2B, and PP2C. At least four isoforms of PP1 catalytic subunit in rat, PP1 $\alpha, \mathrm{PP} 1 \gamma 1, \mathrm{PP} 1 \gamma 2$, and $\mathrm{PP} 1 \delta$, were isolated. In the present study, we examined the localization and expression of PP1 $\delta$ in human osteoblastic Saos-2 cells. Anti-PP1 $\delta$ antibody recognized a protein present in the nucleolar regions in Saos-2 cells. Cellular fractionation revealed that PP1 $\delta$ is a 37 $\mathrm{kDa}$ protein localized in the nucleolus. Nucleophosmin is a nucleolar phosphoprotein and located mainly in the nucleolus. Staining pattern of nucleophosmin in Saos-2 cells was similar to that of PP1 1 . PP1 $\delta$ and nucleophosmin were specifically stained as dots in the nucleus. Dual fluorescence images revealed that PP1 $\delta$ and nucleophosmin were localized in the same regions in the nucleolus. Similar distribution patterns of PP1 $\delta$ and nucleophosmin were observed in osteoblastic MG63 cells. The interaction of PP1 $\delta$ and nucleophosmin was also shown by immunoprecipitation and Western analysis. These results indicated that PP $1 \delta$ associate with nucleophosmin directly in the nucleolus and suggested that nucleophosmin is one of the candidate substrate for PP18.
\end{abstract}

Key words: protein phosphatase, nucleophosmin, osteoblast

\section{Introduction}

Protein dephosphorylation and phosphorylation is a major regulatory mechanism of signal transduction cascades in eukaryotic cells [3, 30]. More than $90 \%$ of the protein phosphatase activity in eukaryotes is due to protein phosphatase-1 (PP1) and -2A (PP2A), which belong to the phosphoprotein phosphatase (PPP) superfamily of serine and threonine protein phosphatases [3, 30]. cDNA cloning revealed that at least four isoforms of $\mathrm{PP} 1$ catalytic subunit, $\mathrm{PP} 1 \alpha, \mathrm{PP} 1 \delta, \mathrm{PP} 1 \gamma 1$, and $\mathrm{PP} 1 \gamma 2$, exist in rat [23]. PP1s are

Correspondence to: Tatsuji Haneji, DDS, Ph.D., Department of Histology and Oral Histology, Institute of Health Biosciences, The University of Tokushima Graduate School, 3-18-15, Kuramoto, Tokushima 770-8504, Japan.

E-mail: tat-hane@dent.tokushima-u.ac.jp involved in cellular processes including glycogen metabolism, muscle contraction, protein synthesis, intracellular transport, and $\mathrm{Ca}^{2+}$ cycling $[2,5]$. The substrates identified for PP1s include glycogen synthase, glycogen phosphorylase, myosin light chain, and ribosomal protein S6 [24]. However, for many other phosphoproteins the contribution of PP1s to their dephosphorylation has yet to be clarified.

The expression of PP1s was previously investigated at the mRNA and protein levels in various tissues [25]. Immunocytochemistry was also carried out in rat cerebellum and salivary glands for PP1 $1 \gamma 1[8,27]$ and in testis for PP $1 \gamma 2$ [26]. In previous studies, we reported the subcellular localization of PP1 isoforms in mouse osteoblastic MC3T3E1 cells and human osteoblastic MG63 cells [6, 17]. PP1 targeting subunits are thought to direct PP1 to specific subcellular components, and to modulate the activity of the 
enzyme at these sites.

Nucleophosmin, also known as B23, has a molecular mass of $38 \mathrm{kDa}$ and is an abundantly expressed phosphoprotein located mainly in the fibrillar components of nucleoli, where it associates with nascent preribosomal RNA [15, 21]. Nucleophosmin is involved in the regulation of ribosome biogenesis, cell proliferation and growth, embryogenesis, cytokinesis, and nucleogenesis [15, 21]. In the present study, we provide evidence showing that nucleophosmin is associated with $\mathrm{PP} 1 \delta$ and is a candidate substrate for this enzyme.

\section{Materials and Methods}

\section{Materials}

Fetal bovine serum (FBS) was obtained from EquitechBio (Kerrville, TX, USA). Alpha-modified Eagle's minimal essential medium ( $\alpha$-MEM) was purchased from Gibco BRL (Grand Island, NY, USA). Plastic dishes were from Iwaki (Chiba, Japan). Protein Assay Reagent and precision plus protein standards were from Bio-Rad (Hercules, CA, USA). Polyvinylidene difluoride (PVDF) transfer membrane was from Millipore (Bedford, MA, USA). Protein A/G PLUS agarose and immunoglobulin $G$ fraction of an antinucleophosmin antibody were purchased from Santa Cruz Biotechnology (Santa Cruz, CA, USA). The antisera against PP1s were those described previously [26]. Anti-PP1 $\delta$ antibody was also developed in our laboratory. Other materials used were of the highest grade commercially available.

\section{Cell culture}

Human osteoblastic cell line Saos-2 [22] was purchased from the American Type Culture Collection (Rockville, MD, USA). The cells were cultured in $\alpha$-MEM containing $10 \%(\mathrm{v} / \mathrm{v}) \mathrm{FBS}, 2 \mathrm{mM}$ glutamine, $100 \mathrm{U} / \mathrm{ml}$ penicillin, and $100 \mu \mathrm{g} / \mathrm{ml}$ streptomycin and were maintained at $37^{\circ} \mathrm{C}$ in a humidified atmosphere of $5 \% \mathrm{CO}_{2}$ and $95 \%$ air. Cell modification was monitored by an Olympus IMT-2 phasecontrast microscope. For immunocytochemistry, the cells were plated on $18-\mathrm{mm}$ round coverslips in $60-\mathrm{mm}$ plastic dishes. For cellular fractionation, Saos- 2 cells growing in $90 \mathrm{~mm}$ plastic dishes were washed twice with $\mathrm{Ca}^{2+}-\mathrm{Mg}^{2+}-$ free phosphate-buffered saline (PBS), scraped into PBS, collected at 3,000 g, and resuspended in hypotonic buffer (20 mM Hepes, pH 7.2, $10 \mathrm{mM} \mathrm{KCl,} 1 \mathrm{mM} \mathrm{MgCl} 2,1 \mathrm{mM}$ DTT, and $0.5 \mathrm{mM}$ EDTA). The cells were allowed to swell for $10 \mathrm{~min}$ on ice before lysis by addition of $0.1 \%$ $\mathrm{NP}-40$ and $100 \mathrm{mM}$ potassium acetate. After $5 \mathrm{~min}$ in ice and vortexing, nuclei were pelleted by centrifugation for $10 \mathrm{~min}$ at $8,000 \mathrm{~g}$, resuspended in lysate buffer containing $1 \mathrm{mM}$ DTT, $1 \mathrm{mM}$ phenylmethylsulfonyl fluoride (PMSF), $1 \mu \mathrm{g} / \mathrm{ml}$ leupeptin, $2 \mu \mathrm{g} / \mathrm{ml}$ aprotinin, and $5 \mathrm{mM}$ EGTA in PBS, and termed the nuclear fraction, whereas the supernatant was termed the cytosolic fraction. The nucleolar fraction was prepared from the purified nuclei according to the method of Muramatsu et al. [18]. The protein concentration of each fraction was evaluated by using Protein Assay
Reagent (Bio-Rad) and diluted to a protein concentration of $1 \mathrm{mg} / \mathrm{ml}$ with lysate buffer before the addition of Laemmli's $5 \times$ sample buffer.

\section{Immunoprecipitation}

Cells cultured in 90-mm plastic dishes were washed twice with PBS, scraped into PBS, pelleted at 3,000 g, and resuspended in $500 \mu \mathrm{l}$ of lysis buffer $(150 \mathrm{mM} \mathrm{NaCl}, 1.0 \%$ NP-40, $50 \mathrm{mM}$ Tris- $\mathrm{HCl}$ [pH 8.0], $50 \mathrm{mM} \mathrm{NaF}$, and $1 \mathrm{mM}$ $\mathrm{Na}_{3} \mathrm{VO}_{4}$ ). The lysate was pre-treated for $60 \mathrm{~min}$ with protein $\mathrm{A} / \mathrm{G}$ PLUS agarose at $4^{\circ} \mathrm{C}$ and then incubated with $2 \mu \mathrm{l}$ of anti-PP1 $\delta$ or anti-nucleophosmin antibodies. The reaction mixture was incubated for overnight at $4{ }^{\circ} \mathrm{C}$ with $10 \mu \mathrm{l}$ of protein A/G PLUS agarose. The immunocomplexes were washed 5 times with lysis buffer and resuspended in $40 \mu \mathrm{l}$ of SDS electrophoresis sample buffer. The samples were boiled for $5 \mathrm{~min}$ and the supernatant was analyzed by SDSPAGE and Western blotting using the anti-nucleophosmin or anti-PP1 $\delta$ antibodies.

\section{SDS-PAGE and Western analysis}

Ten $\mu \mathrm{g}$ of each sample and pre-stained protein markers were separated by SDS-PAGE and transferred to PVDF membranes. The membranes were blocked in a solution containing 5\% nonfat skim milk in PBS-Tween for $2 \mathrm{hr}$ at ambient temperature. They were washed briefly in PBS containing $0.05 \%$ Tween-20 (PBS-Tween) and incubated overnight at $4{ }^{\circ} \mathrm{C}$ in a blocking solution containing anti-PP1 $\delta$ antibody diluted 1:2,000 or anti-nucleophosmin antibody at 1:1,000 dilutions. The membranes were washed four times within $30 \mathrm{~min}$ in PBS-Tween on a rotary shaker at ambient temperature. The washed membranes were incubated for 2 hr with horseradish peroxidase (HRP)-conjugated anti-rabbit IgG for PP1 $\delta$ or anti-goat IgG for nucleophosmin (both diluted 1:5,000 in a blocking solution) at ambient temperature. The membranes were washed as described, and the proteins recognized by the antibodies were visualized by using an ECL detection kit according to the manufacturer's directions.

\section{Immunocytochemistry}

The cells on coverslips were washed three times with PBS and fixed with $3.7 \%$ formaldehyde for $10 \mathrm{~min}$ at ambient temperature followed by methanol-permeabilization for an additional $20 \mathrm{~min}$ at $-20^{\circ} \mathrm{C}$. Non-specific binding sites were blocked with $4 \% \mathrm{BSA}$ in PBS for $10 \mathrm{~min}$ at ambient temperature. Having been rinsed with cold PBS, the coverslips were incubated simultaneously with antiPP1 $\delta$ antibody diluted $1: 200$ and $5 \mu \mathrm{g} / \mathrm{ml}$ of the IgG fraction of anti-nucleophosmin antibody in 4\% BSA for 45 min at ambient temperature. After three washes with $0.1 \%$ BSA in PBS-Tween over a 15-min period at ambient temperature, the cells were incubated with a mixture of tetramethylrhodamine isothiocyanate (TRITC, rhodamine)conjugated sheep anti-rabbit IgG (Chemicon International, Temecula, CA, USA) and fluorescein isothiocyanate (FITC)conjugated goat anti-mouse IgG (Cappel-Organon Teknika, 
Turnhout, Belgium), both diluted 1:300 in 4\% BSA in PBS for another $45 \mathrm{~min}$ at ambient temperature. The coverslips were washed as described above and mounted while wet with PermaFluor aqueous mounting medium (Lipshow, Pittsburgh, PA, USA). The samples were examined under an Olympus BX50 microscope equipped with epifluorescence illumination (BX-FLA) with a U-MWIG filter for rhodamine and a U-MNIBA filter for FITC. The U-MNIBA filter separates FITC from rhodamine or Texas Red. The staining reaction was not observed when FITC-labeled cells were examined with a filter for rhodamine (the U-MWIG filter). Rhodamine-labeled cells were not detected with a filter for FITC (the U-MNIBA filter). Microphotographs were recorded on a computer (Olympus, DP70-WPCXP).

\section{Results}

\section{Localization of PP1 isotypes in Saos-2 cells}

To examine the cytolocalization of PP1 isotypes in human osteoblastic cells, Saos- 2 cells at monolayer were fixed, permeabilized, and stained with the rabbit polyclonal antibodies against the catalytic subunits of PP $1 \alpha, \operatorname{PP} 1 \gamma 1$, PP1 $\gamma 2$, and PP1 $\delta$. The immunereactivity of each isotype showed quite different cellular distributions. Although a weak staining was observed in the cytoplasm, the distribution of PP1 $\alpha$ was mainly in the nucleus (Fig. 1a). PP1 $\gamma 1$ was localized in both the nucleus and the cytoplasm. The punctuated distribution of PP $1 \gamma 1$ in cytoplasm was especially distinct in the perinuclear region. The staining reaction in the cytoplasm was much stronger than that which occurred in the nucleus (Fig. 1b). Intense staining occurred in the nucleus with the anti-PP $1 \delta$ antibody. PP $1 \delta$ was specifically stained as dots in the nucleus that may represent nucleoli (Fig. 1c). The immunoreaction was not observed with antiPP1 $\gamma 2$ antibody (Fig. 1d) and the normal rabbit serum (data not shown). That the distribution of PP1s is not limited to Saos- 2 cells was confirmed by the fact that they had an identical distribution in MG63 human osteoblastic cells (Fig. 2) or mouse osteoblastic MC3T3-E1 cells (data not shown).

\section{Detection of PP1 isoforms in subcellular fractions}

Because PP1 $\delta$ showed specific localization in Saos-2 cells as described above, we determined the subcellular localization of PP $1 \delta$ protein by using cellular fractions including cytoplasmic, nuclear, and nucleolar fractions prepared from cultured Saos- 2 cells. Twenty $\mu \mathrm{g}$ of proteins obtained from each fraction were subjected to SDS-PAGE and followed by Western analysis. Figure 3 shows that the antibody reacted with a major band corresponding to the estimated molecular weight of $37 \mathrm{kDa}$. Although the reaction was observed in the nuclear fraction, the strongest interaction was observed in the nucleolar fraction. Very little immunoreactive proteins were detected in the cytosolic fraction.
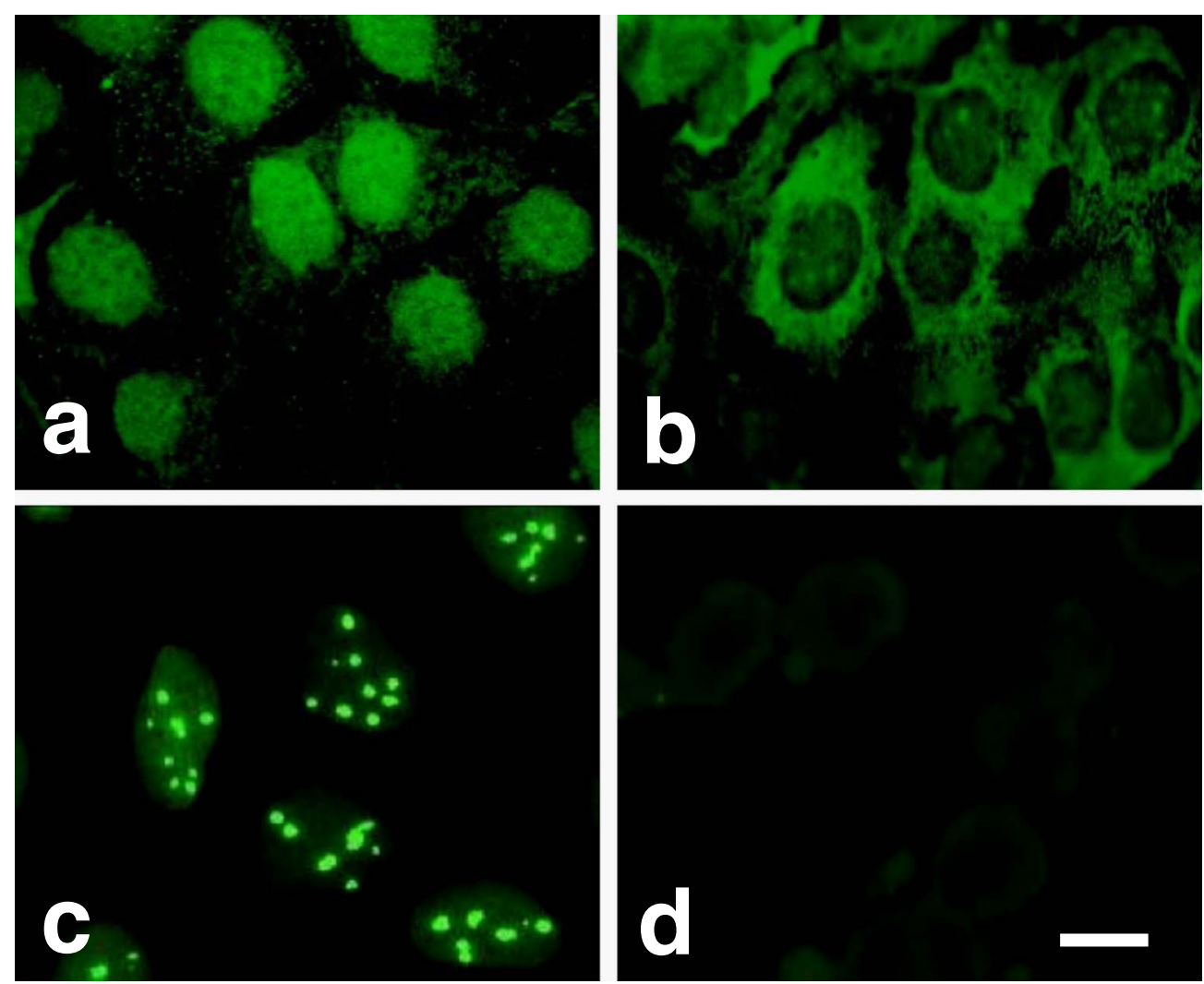

Fig. 1. Localization of PP1 isotypes in Saos-2 cells. Saos-2 cells at monolayer were fixed, permeabilized, and stained with the rabbit polyclonal antibodies against the catalytic subunits of PP1 $\alpha$ (a), PP1 $\gamma 1$ (b), PP1 $\delta(\mathbf{c})$, and PP $1 \gamma 2(\mathbf{d})$. Bar=10 $\mu \mathrm{m}$ 

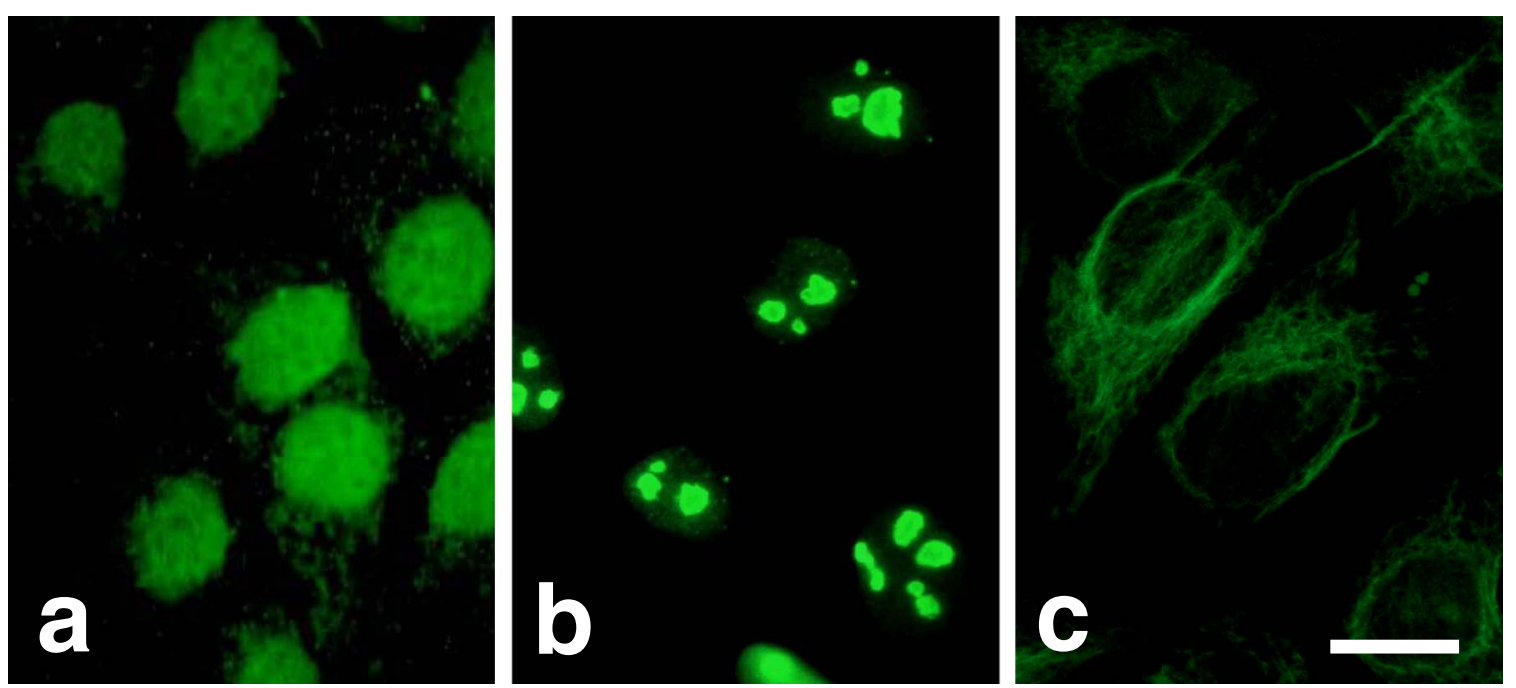

Fig. 2. Localization of PP1 isotypes in MG63 cells. MG63 cells were stained with antibodies against PP1 $\alpha(\mathbf{a})$, PP1 $\delta$ (b), and PP1 $\gamma 1$ (c). Bar $=10 \mu \mathrm{m}$.

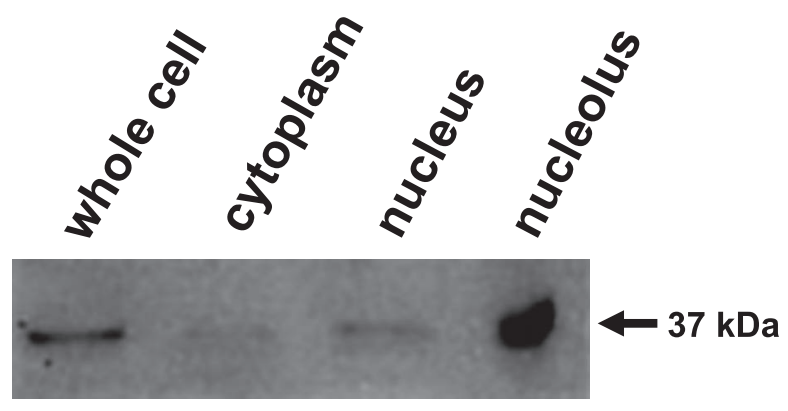

Fig. 3. Detection of PP1 $\delta$ in subcellular fractions of Saos-2 cells. Cytoplasmic, nuclear, and nucleolar fractions were prepared from Saos-2 cells. Whole cell lysate and proteins obtained from each fraction were subjected to Western analysis. The intense positive reaction was detected in the nucleolar fraction.

Normal rabbit serum did not recognize any proteins prepared from cultured Saos-2 cells (data not shown).

\section{Co-localization of PP1S and nucleophosmin in Saos-2 cells}

In the previous reports, we and others demonstrated that PP1 $\delta$ localized in nucleolus in mouse osteoblastic MC3T3-E1 cells and Swiss 3T3 cells [6, 14]. This distribution pattern was similar to that of nucleolin, nucleophosmin, or AgNORs. To examine whether PP1 $\delta$ and nucleophosmin would be localized at the same site in the nucleolus, we fixed, permeabilized, and stained the cultured Saos- 2 cells with the anti-PP1 $\delta$ antibody and anti-nucleophosmin antibody. Figure 4 shows the distribution of PP1 $\delta$ and nucleophosmin in Saos-2 cells. With anti-PP1 $\delta$ antibody, nucleolus-like bodies were intensely stained and visible as red fluorescence from due to the rhodamine-conjugated second antibody (Fig. 4a). An antinucleophosmin antibody stained the same sites of the PP1 $\delta$ positive regions, which gave a green fluorescence because
FITC-conjugated second antibody was used (Fig. 4b). The merged view confirmed that PP1 $\delta$ and nucleophosmin were localized in the same sites in Saos- 2 cells because the reaction was visible as yellow (Fig. 4c). Figure 4 also shows that anti-PP1 $\delta$ antibody and anti-nucleophosmin antibody stained the nucleolus-like materials in MG63 cells (Fig. 4d and 4e). The positive sites were stained as yellow in the merged view indicating that PP1 $\delta$ and nucleophosmin were also localized in the same sites in MG63 cells (Fig. 4f). The staining reaction was not observed when normal rabbit serum or normal goat serum was used as a primary antibody both in Saos-2 and MG63 cells (data not shown).

\section{PP1 $\delta$ associates with nucleophosmin}

To determine whether PP1 $\delta$ could associate with nucleophosmin, whole cell lysate prepared from cultured Saos- 2 cells was immunoprecipitated with the anti-PP1 $\delta$ antibody or with the anti-nucleophosmin antibody. The immunoprecipitants were analysed by Western blotting using the anti-nucleophosmin antibody (Fig. 5A) or antiPP1 $\delta$ antibody (Fig. 5B). Anti-nucleophosmin antibody interacted with a protein precipitated with the anti-PP $1 \delta$ antibody. However, this antibody did not recognize any proteins precipitated with the normal goat IgG. The molecular weight of the interacting protein was estimated as $38 \mathrm{kDa}$ which corresponded to the molecular weight of nucleophosmin. Anti-PP1 $\delta$ antibody interacted with a protein precipitated with the anti-nucleophosmin antibody. The molecular weight of the interacting protein was estimated as $37 \mathrm{kDa}$ which corresponded to PP1 $\delta$. Anti-PP1 $\delta$ antibody did not interact with the proteins precipitated with the normal rabbit IgG. As positive controls, the results of whole cell lysate stained with the anti-nucleophosmin antibody and anti-PP1 $\delta$ antibody are also shown in Figure 5A and 5B, respectively. 

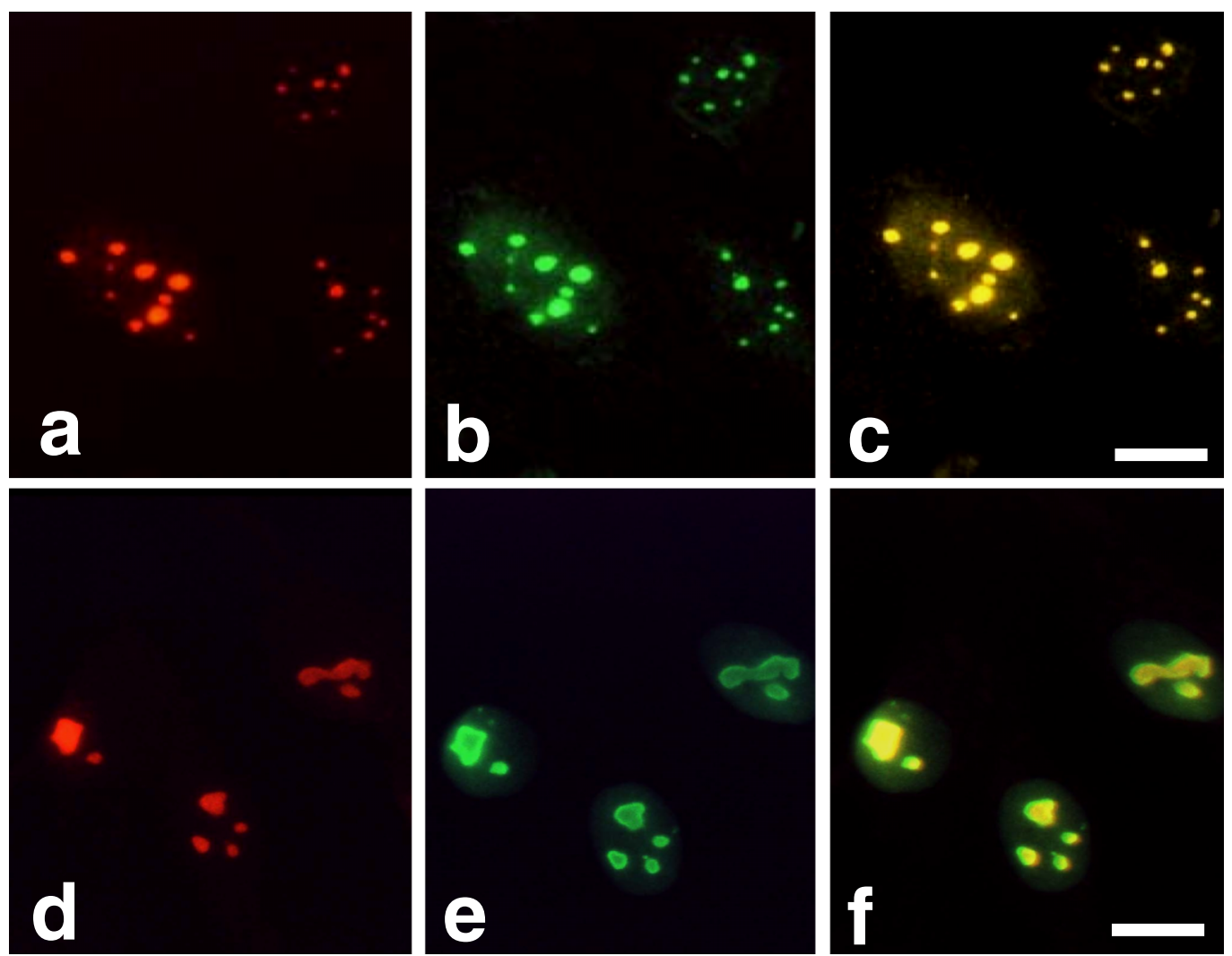

Fig. 4. Co-localization of PP1 $\delta$ and nucleophosmin in Saos-2 and MG63 cells. Saos-2 cells (upper panel) and MG63 cells (lower panel) were stained with anti-PP1 $\delta$ antibody followed by the rhodamine-conjugated second antibody (a and $\mathbf{d})$. The same cultures were also stained with the anti-nucleophosmin antibody followed by the FITC-conjugated second antibody (b and $\mathbf{e}$ ). The merged view of Figures $\mathbf{a}$ and $\mathbf{b}$ and Figures $\mathbf{d}$ and $\mathbf{e}$ are shown in Figure $\mathbf{c}$ and Figure $\mathbf{f}$, respectively. Bars $=10 \mu \mathrm{m}$.

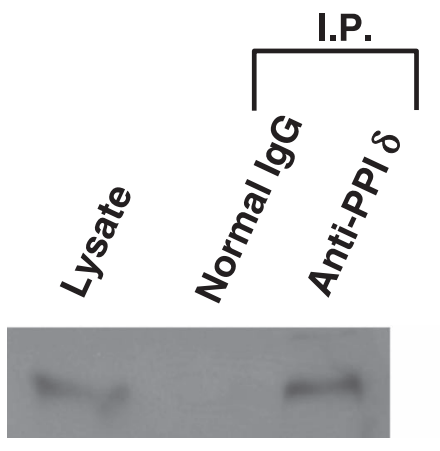

W.B. Anti-NPS

A

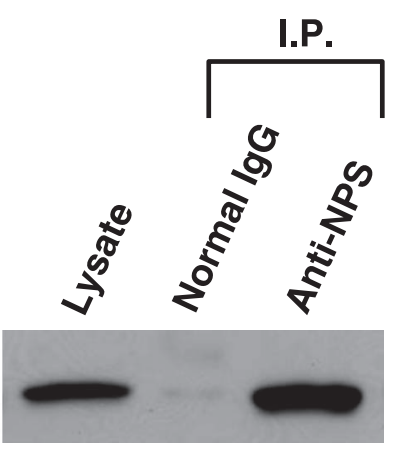

W.B. Anti-PP1 $\delta$

B

Fig. 5. PP1 $\delta$ interacts with nucleophosmin. Whole cell lysate prepared from Saos-2 cells was immunoprecipitated with the anti-PP1 $\delta$ antibody and normal rabbit $\operatorname{IgG}(\mathbf{A})$ or with the antinucleophosmin (NPS) antibody and normal goat $\operatorname{IgG}(\mathbf{B})$. The immunoprecipitants were analysed by Western blotting using the anti-NPS antibody (A) or anti-PP1 $\delta$ antibody (B). As a positive control, whole cell lysate was used as input.

\section{Discussion}

The specific localization of the catalytic subunit of PP1 $\delta$ in nucleoli in Saos-2 and MG63 cells indicates that the nucleolus is the site where this enzyme functions. These findings confirm our previous results [6] and those of others $[14,19]$. The antibody used in the latter reports was raised against the peptide with additional three amino acids to the peptide that we had used to raise the antibody. However, other studies reported that PP $1 \gamma 1$ rather than PP $1 \delta$ localized within the nucleolus $[1,29]$. The differences of the results obtained from the independent laboratory may be explained in part by the specificity of the antibody used and different conditions used in the independent experiment. The process regulating the nucleolar location of PP1 $\delta$ is quite interesting. It should be noted that PP $1 \delta$ does not exhibit any evidence of nuclear localization signals in its sequence [23, 25]. However, proteins the sizes of catalytic subunit of PP1 $\delta$ have been shown to freely diffuse into the nucleus without the necessity for specific translocation sequences. The noncatalytic subunits of PP1s have a targeting function, enabling the phosphatases to associate with a particular cellular fraction. Once in the nuclei, PP1s bind to immobile components to maintain their nuclear localization. The highest concentration of PP1s is found in the nucleus, where 
the enzymes are both in the nucleoplasm and associated with heterochromatin [12]. PP1 activity increased in the nuclei of hepatocyte primary cultures stimulated by EGF, whereas no isoforms showed any changes in concentration under these conditions [13]. The nucleolar activity of PP1s including PP1 $\delta$ is not known at present.

We paid much attention to the relationship between PP1 $\delta$ and nucleophosmin in the present study. We demonstrated that PP1 $\delta$ was localized in the nucleolus in the cultured Saos- 2 cells and that this enzyme was associated with nucleophosmin. The function of PP1s depends on the localization of these enzymes in cells. As with protein kinases and other enzymes, protein phosphatases should be associated with or located near to their substrates [9, $11,20]$, hence the substrates of PP1 $\delta$ should be present in the nucleolus. PP1 binding proteins are thought to have an R/KV/IXF, R/KXV/IF [4] or IKGI [10, 28] motif; however, such motifs are not identified in nucleophosmin. The association between PP1 $\delta$ and nucleophosmin should be indirect and some regulatory subunits could exist that allow PP $1 \delta$ to bind to nucleophosmin. However, there still remains the possibility that nucleophosmin binds directly to PP1 $\delta$ by some unknown binding domains or mechanisms. The interaction between PP1 $\delta$ and nucleophosmin demonstrated by immunoprecipitation and Western analysis suggests the possibility that PP1 $\delta$ is the enzyme that dephosphorylates nucleophosmin. It was recently reported that PP1 $\beta(\delta)$ dephosphorylated nucleophosmin both in the genotoxic stress and growth conditions that facilitated DNA repair [16]. Although it is not clear whether or not the $38-\mathrm{kDa}$ protein is a dephosphorylated form of nucleophosmin, the amount of a $38-\mathrm{kDa}$ protein decreased by the protein phosphatase inhibitor okadaic acid-treated Saos-2 cells (unpublished data). These findings suggest that nucleophosmin could be partially dephosphorylated into a $38-\mathrm{kDa}$ protein detected with an anti-nucleophosmin antibody. This does not rule out the possibility that nucleophosmin is partially proteolyzed into a $38-\mathrm{kDa}$ protein. It was also reported that localization of PP1 $\delta$ is similar to that of nucleolin (C23) and that nucleolin could be a candidate substrate for PP1 $\delta[7,17]$

\section{Acknowledgments}

We wish to thank Ms. Eiko Sasaki for her skillful technical assistance. This study was supported in part by grants from the Grant-in-Aid for Scientific Research from the Ministry of Education, Science, Sports, and Culture of Japan (TH and HM).

\section{References}

1. Andreassen, P. R., Lacroix, F. B., Villa-Moruzzi, E. and Margolis, R. L. (1998) Differential subcellular localization of protein phosphatase- $1 \alpha, \gamma 1$, and $\delta$ isoforms during both interphase and mitosis in mammalian cells. J. Cell Biol. 141; 1207-1215.

2. Aoyama, H., Ikeda, Y., Miyazaki, Y., Yoshimura, K., Nishio,
S., Yamamoto, T., Yano, M., Inui, M., Aoki, H. and Matsuzaki, M. (2010) Isoform-specific roles of protein phosphatase 1 catalytic subunits in sarcoplasmic reticulum-mediated $\mathrm{Ca}^{2+}$ cycling. Cardiovasc. Res. 89; 79-88.

3. Bollen, M., Peti, W., Ragusa, M. J. and Beullens, M. (2010) The extended PP1 toolkit: designed to create specificity. Trends Biochem. Sci. 35; 450-458.

4. Egloff, M. P., Johnson, D. F., Moorhead, G., Cohen, P. T., Cohen, P. and Barford, D. (1997) Structural basis of the recognition of regulatory subunits by the catalytic subunit of protein phosphatase 1. EMBO J. 16; 1876-1887.

5. Fardilha, M., Esteves, S. L., Korrodi-Gregório, L., da Cruz e Silva, O. A. and da Cruz e Silva, F. F. (2010) The physiological relevance of protein phosphatase 1 and its interacting proteins to health and disease. Curr. Med. Chem. 17; 3996-4017.

6. Haneji, T., Morimoto, H., Morimoto, Y., Shirakawa, S., Kobayashi, S., Kaneda, C., Shima, H. and Nagao, M. (1998) Subcellular localization of protein phosphatase type 1 isotypes in mouse osteoblastic cells. Biochem. Biophys. Res. Commun. 248; 39-43.

7. Haneji, T. (2005) Association of protein phosphatase 1 delta with nucleolin in osteoblastic cells and cleavage of nucleolin in apoptosis-induced osteoblastic cells. Acta Histochem. Cytochem. $38 ; 1-8$.

8. Hashikawa, T., Nakazawa, K., Mikawa, S., Shima, H. and Nagao, M. (1993) Immunohistochemical localization of protein phosphatase isoforms in the rat cerebellum. Neurosci. Res. 22; 133136.

9. Hata, M., Amano, I., Tsuruga, E., Kojima, H. and Sawa, Y. (2010) Immunoelectron microscopic study of podoplanin localization in mouse salivary gland myoepithelium. Acta Histochem. Cytochem. 43; 77-82.

10. Huang, H. B., Horiuchi, A., Watanabe, T., Shih, S. R., Tsay, H. J., Li, H. C., Greengard, P. and Nairn, A. C. (1999) Characterization of the inhibition of protein phosphatase-1 by DARPP-32 and inhibitor-2. J. Biol. Chem. 274; 7870-7878.

11. Inagaki, N., Ito, M., Nakano, T. and Inagaki, M. (1994) Spatiotemporal distribution of protein kinase and phosphatase activities. Trends Biochem. Sci. 19; 448-452.

12. Jagiello, I., Beullens, M., Stalmans, W. and Bollen, M. (1995) Subunit structure and regulation of protein phosphatase-1 in rat liver nuclei. J. Biol. Chem. 270; 17257-17263.

13. Kakinoki, Y., Mizuno, Y., Takizawa, N., Imai, Y., Miyazaki, T. and Kikuchi, K. (1994) TGF1 suppresses EGF-induced increase in nuclear type 1 protein phosphatase activity at the $\mathrm{G} 1 / \mathrm{S}$ transition of hepatocyte proliferation. FEBS Lett. 352; 356-360.

14. Kotani, H., Ito, M., Hamaguchi, T., Ichikawa, K., Nakano, T., Shima, H., Nagao, M., Ohta, N., Furuichi, Y., Takahashi, T. and Umekawa, H. (1998) The $\delta$ isoform of protein phosphatase type 1 is localized in nucleolus and dephosphorylates nucleolar phosphoproteins. Biochem. Biophys. Res. Commun. 249; 292-296.

15. Lim, M. J. and Wang, X. W. (2006) Nucleophosmin and human cancer. Cancer Detect. Prev. 30; 481-490.

16. Lin, C. Y., Tan, B. C. M., Liu, H., Shih, C. J., Chien, K. Y., Lin, C. L. and Yung, B. Y. M. (2010) Dephosphorylation of nucleophosmin by PP1 $\beta$ facilitates $\mathrm{pRB}$ binding and consequent E2F1dependent DNA repair. Mol. Biol. Cell 21; 4409-4417.

17. Morimoto, H., Okamura, H. and Haneji, T. (2002) Interaction of protein phosphatase 1 delta with nucleolin in osteoblastic cells. J. Histochem. Cytochem. 50; 1187-1193.

18. Muramatsu, M., Hayashi, Y., Onishi, T., Sakai, M. and Takai, K. (1974) Rapid isolation of nucleoli from detergent purified nuclei of various tumor and tissue culture cells. Exp. Cell Res. 88; 245251.

19. Murányi, A., Erdodi, F., Ito, M., Gergely, P. and Hartshorne, D. J. (1998) Identification and localization of myosin phosphatase in 
human platelets. Biochem. J. 330; 225-231

20. Noda, Y., Amano, I., Hata, M., Kojima, H. and Sawa, Y. (2010) Immunohistochemical examination on the distribution of cells expressed lymphatic endothelial marker podoplanin and LYVE-1 in the mouse tongue tissue. Acta Histochem. Cytochem. 43; 6168 .

21. Okuwaki, M. (2008) The structure and functions of MPM1/ Nucleophosmin/B23, a multifunctional nucleolar acidic protein. J. Biochem. 143; 441-448.

22. Rodan, S. B., Imai, Y., Thiede, M. A., Wesolowski, G., Thompson, D., Bar-Shavit, Z., Shull, S., Mann, K. and Rodan, G. A. (1987) Characterization of human osteosarcoma cell line (Saos-2) with osteoblastic properties. Cancer Res. 47; 49614966.

23. Sasaki, K., Shima, H., Kitagawa, Y., Irino, S., Sugimura, T. and Nagao, M. (1990) Identification of members of the protein phosphatase 1 gene family in the rat and enhanced expression of protein phosphatase $1 \alpha$ gene in rat hepatocellular carcinomas. Jpn. J. Cancer Res. 81; 1272-1280.

24. Shi, Y. (2009) Serine/threonine phosphatases: mechanism through structure. Cell 139; 468-484.

25. Shima, H., Hatano, Y., Chun, Y. S., Sugimura, T., Zang, Z., Lee, E. Y. C. and Nagao, M. (1993) Identification of PP1 catalytic subunit isotypes PP $1 \gamma 1, \mathrm{PP} 1 \delta$ and PP $1 \alpha$ in various rat tissues. Biochem. Biophys. Res. Commun. 192; 1289-1296.
26. Shima, H., Haneji, T., Hatano, Y., Kasugai, I., Sugimura, T. and Nagao, M. (1993) Protein phosphatase $1 \gamma 2$ is associated with nuclei of meiotic cells in rat testis. Biochem. Biophys. Res. Commun. 194; 930-937.

27. Shirakawa, S., Mochizuki, H., Kobayashi, S., Takehara, T., Shima, H., Nagao, M. and Haneji, T. (1996) Immunohistochemical and immunoblotting identification of protein phosphatase $1 \gamma 1$ in rat salivary glands. FEBS Lett. 393; 57-59.

28. Shirato, H., Shima, H., Sakashita, G., Nakano, T., Ito, M., Lee, E. Y. C. and Kikuchi, K. (2000) Identification and characterization of a novel protein inhibitor of type 1 protein phosphatase. Biochemistry 39; 13848-13855.

29. Trinkle-Mulcahy, L., Sleeman, J. E. and Lamond, A. I. (2001) Dynamic targeting of protein phosphatase 1 within the nuclei of living mammalian cells. J. Cell Sci. 114; 4219-4228.

30. Virshup, D. M. and Shenolikar, S. (2009) From promiscuity to precision: protein phosphatases get a makeover. Mol. Cell. 33; $537-545$.

This is an open access article distributed under the Creative Commons Attribution License, which permits unrestricted use, distribution, and reproduction in any medium, provided the original work is properly cited. 